\title{
O interesse das revistas brasileiras e francesas de biblioteconomia e ciências da informação pela revista eletrônica no período de 1990-1999
}

\section{Estera Muszkat Menezes Viviane Couzinet}

\section{Resumo}

A revista científica tem sido o tema objeto de muitas publicações nas revistas de ciências da informação brasileiras e francesas. Uma revisão da literatura da produção científica nesse assunto mostra como a revista eletrônica é levada em conta na pesquisa no Brasil e na França.

\section{Palavras-chave}

Publicações eletrônicas; Ciência da informação; Biblioteconomia; Brasil; França.

\section{INTRODUÇÃO}

O periódico científico é o meio mais utilizado para a difusão de resultados de pesquisa e para a comunicação entre pares da "comunidade científica". Esta importância dada à revistafoi muito marcante, no Brasil, no período 19601970. Após uma diminuição dos recursos, nota-se, atualmente, uma elevação destes às publicações periódicas para difundir os conhecimentos produzidos, paralelamente ao desenvolvimento da utilização das tecnologias da informação e da comunicação (Mueller, 1994). Estes periódicos, permitindo o estabelecimento de maiores contatos, mais rápidos e mais eficazes, contribuem para o crescimento da produção de artigos.

$\mathrm{Na}$ França, a revista científica foi o tema de numerosos trabalhos. Desde 1992, ele é um dos objetos de investigação de uma equipe de pesquisadores em ciência da informação e da comunicação que trabalha no núcleo do Laboratório de Estudos e Pesquisas Aplicadas em Ciências Sociais - Lerass (Université Paul Sabatier, Institut Universitaire de Technologie, Toulouse). Os intercâmbios estabelecidos entre a equipe do Lerass, denominados ICC (Informação e Comunicação entre Pesquisadores) e um professor/pesquisador brasileiro permitiram salientar a importância da revista científica para as comunidades de pesquisadores de ciências da informação brasileiros e franceses.
Que interesse a pesquisa em biblioteconomia e em ciências da informação brasileiros e franceses têm na revista científica e, mais particularmente, na revista científica eletrônica? Isto é, o que se propõe mostrar esta contribuição a partir de uma revisão de artigos publicados em revistas brasileiras e francesas sobre o assunto.

\section{AS REVISTAS DE CIÊNCIAS DA INFORMAÇÃO}

O material deste estudo compõe-se de artigos provenientes de revistas da área de biblioteconomia e ciência da informação correntes disponíveis nos dois países.

Entre os periódicos brasileiros existentes no domínio que nos interessa, procedemos a uma primeira seleção a partir da base de dados no Library and Information Science Abstracts* (Lisa), no período, 1990-1999. Para este período, quatro revistas são referenciadas no Lisa:

\footnotetext{
* Existem outros periódicos de ciência da informação e de biblioteconomia no Brasil, como, por exemplo, Transinformação, revista do Departamento de Pós-graduação em Biblioteconomia da Universidade Católica (Campinas), Biblos, revista do Departamento de Biblioteconomia e História (Rio Grande), Revista de Biblioteconomia \& Comunicação da Universidade Federal do Rio Grande do Sul (Porto Alegre).
} 
- A Revista de Biblioteconomia de Brasília, publicada pela Associação dos Bibliotecários do Distrito Federal (ABDF) e pelo Departamento de Ciências da Informação e da Documentação da Universidade de Brasília. Esta revista é indexada também em Índices de revistas de Bibliotecologia; Information Science Abstract; Library Literature; Sumários de Periódicos em Biblioteconomia. Para o período considerado, um só artigo acerca do assunto foi publicado, em 1995. A publicação desta revista foi suspensa de 1991 a 1994, sendo reativada em 1996 com uma só publicação, assim como em 1997, e reativada novamente em 1998, com a publicação de um só número.

- A Revista Brasileira de Biblioteconomia e Documentação, da Federação Brasileira de Associações de Bibliotecários (Febab), não publicou em 1990 e 1991 artigos sobre o assunto em pauta. De 1992 a 1999, nenhum artigo desta revista foi indexado.

- A Revista da Escola de Biblioteconomia da Universidade Federal de Minas Gerais. Indexada também em $A B C D$ resumos e sumários; Bibliografia Brasileira de Ciência da Informação; Banbi: Banco de informação; Índices de Revistas de Bibliotecologia; Information Science Abstract; Library literature; Sumários Correntes Brasileiros. No período de 1990 a 1995, ela nada publicou sobre o assunto em questão. Para o ano de 1996, a pesquisa foi efetuada no periódico Perspectivas em Ciência da Informação, novo título desta revista, a partir de janeiro, onde nada encontramos, assim como no ano de 1997. Em 1998, encontramos apenas um artigo e no primeiro semestre de 1999, o enfoque também não foi para este assunto.

- A revista Ciência da Informação, revista publicada pelo Instituto Brasileiro de Informação em Ciência e Tecnologia $($ IBICT)* e indexada também no Pascal - Sciences de l'information; $P A I S$ foreign language index; Information science abstract; library literature; Páginas de contenido: Ciências de

\footnotetext{
* O IBICT é o equivalente, na França, ao INST - Institut National de L'information Scientifique et Technique, subordinado ao Ministére de I'Education et de la Recherche
}

la información; Educación: notícias de educación, ciência y cultura iberoamericana; Referativnyi Zhurnal: Informatika. Foram publicados 28 artigos sobre o assunto que nos interessa : três em 1990, dois em 1992, dois em 1993, quatro em 1994, dois em 1995 e quatro em 1996; em 1997 nada consta; em 1998 grande ênfase foi dada ao assunto pesquisado, com 11 publicações, e no ano de 1999 nada consta até o presente momento.

Escolhemos a revista Ciência da Informação devido ao fato de este periódico ter sido indexado regularmente no Lisa, ter uma periodicidade constante e apresentar um interesse particular pela revista científica.

$\mathrm{Na}$ França, apenas duas revistas beneficiam-se de uma notoriedade suficiente para publicar trabalhos de pesquisadores e de profissionais de alto nível.

- O Bulletin des bibliothéques de France, produzido pela École Nationale Supérieure des Sciences de l'information et des Bibliothéques (ENS$\mathrm{SIB}$ ), é indexado pelo banco de dados Pascal do Centre Nationale de Recherche Scientifique (CNRS) e no Lisa. Sua publicação é regular e sua indexação neste dois bancos de dados é sistemática. Para o período escolhido, selecionamos dez artigos: um em 1990, dois em 1992, dois em 1994, um em 1995 e quatro em 1996.

- Documentaliste - Sciences de l'informationé a revista da Associação francesa de profissionais da informação e da documentação (ADBS). Esta associação é que agrupa o maior número de profissionais da especialidade, na França. A revista é muito aberta à pesquisa e é indexada em Pascal e no Lisa de maneira regular. Alguns de seus artigos são também indexados na Revista española de documentacíon científica do Consejo Superior de Investigaciones Científicas (Madri). Consideramos para esta pesquisa oito artigos ao total: um para 1990, três para 1994, dois para 1995, um para 1996 e um para 1999.

O conjunto deste estudo tem, portan- to, 46 . Nestes artigos, a revista é abordada seguindo dois temas particulares, seu uso pelos pesquisadores e o papel da revista eletrônica na pesquisa científica.

\section{UTILIZAÇÃO DAS REVISTAS PELOS PESQUISADORES}

\section{Revista e pesquisa científica}

Noris Foresti (1990) mostrou a importância das revistas de biblioteconomia e de ciências da informação brasileiras como fonte de referência para a pesquisa, a partir da análise das citações que acompanhavam os trabalhos publicados nestas revistas de 1983 a 1987. Das 372 contribuições consideradas por esta análise, citando 4.459 artigos, conclui-se que o periódico é a fonte essencial para a pesquisa na ciência da informação no Brasil. Vários estudos relacionados na Ciência da Informação realizados por professores e pesquisadores de disciplinas diversas confirmam esta conclusão.

Maria Rodrigues e Jana Mualem (1993), por exemplo, afirmam que a revista é o meio mais utilizado pelos pesquisadores da Universidade Federal do Maranhão para a pesquisa e a difusão de seus trabalhos. Da mesma forma, Helena Souza (1990), em uma análise da produção científica durante o período compreendido entre 1972 e 1985, analisou nos catálogos de dissertações e de teses de ciências da informação e biblioteconomia comparando-os com a Bibliografia Brasileira de Documentação (BBD)* e a Bibliografia Brasileira de Ciência da Informação (BBCl). Esta análise mostra que a preferência dos autores é de publicar em revistas especializadas. Na Universidade Federal da Bahia, a produção científica dos professores foi analisada por Margarida Oliveira e Esmeralda Aragão (1992). Elas identificaram as barreiras que interferem na comunicação destes pesquisadores e suas fontes de informações bibliográficas mais utilizadas. As autoras mostram que é a Rede de Informação Latino-Americana e do Caribe em Ciência da Saúde* que facilita a pesquisa da informação

\footnotetext{
* Esta bibliografia é produzida pela Biblioteca Nacional do Brasil.
} 
em linha e que permite, assim, o acesso aos artigos de revistas.

Em uma abordagem mais teórica, para Marcos Ramos (1994), a ciência é "um processo contínuo de reinterpretação cultural do meio no qual os cientistas batizam sua versão do mundo físico". Este autor apresenta três modelos de comunicação e de difusão da produção científica que coexistem: 1) o sistema de comunicação vital para a ciência - situa-se no centro do processo científico, e o meio característico de comunicação de resultados da pesquisa é o artigo publicado em uma revista; 2) este modelo "difusionista" é completado pelo modelo "dialético" desenvolvido por Bourdieu, para o qual o domínio científico é um lugar de luta entre dois grupos distintos, "grupos dos quais os agentes são desigualmente dotados de um capital científico e, portanto, desigualmente capazes de se apropriar do produto do trabalho científico..."; 3) Ramos propõe o modelo "científico vulgarisacionista", no qual se trata de utilizar todos os processos disponíveis para veicular a informação científica e técnica. A extensão do conceito de IST permite, segundo Ramos, a integração dos periódicos especializados, do jornalismo científico, dos bancos de dados, das unidades de informação (bibliotecas e centros de documentação).

A utilização de revistas é o tema de um estudo empírico desenvolvido por três pesquisadores franceses de ciências da informação e da comunicação (Couzinet Viviane, Bouzon Arlette e Normand Raoul, 1996). Meio essencial para a pesquisa, a revista é utilizada de forma intensa pelos estudantes que preparam uma tese. As pesquisas realizadas junto a este público revelam que há dificuldades em se encontrarem referências úteis.

Utilizada por pesquisadores para conhecer e fazer com que se conheça a

\footnotetext{
* Rede que sucedeu a Bireme, Biblioteca Regional de Medicina.
}

pesquisa científica, a revista serve também de suporte de avaliação da atividade de investigação. A partir de um estudo bibliométrico da produção de artigos de várias autorias encontrados em revistas internacionais, é possível, por exemplo, avaliar as colaborações estabelecidas entre um laboratório e pesquisadores estrangeiros (Vergnes Gisele, Picard Francis, Mosseti Michel, 1990). A análise quantitativa dos artigos publicados em revistas internacionais permite verificar as posições ocupadas das publicações de um grupo de pesquisadores (Remy Danielle, RING Blanche, Vergnes Gisele, 1996). No caso da saúde, Jean Dominique Pierret, Gerard Hilaire, Luc Quoniam e Henri Dou (1994) colocaram em evidência os títulos que abordam exaustivamente determinado assunto. A partir destes resultados, é possível se localizarem centros de excelência na área, orientar as escolhas de assinaturas, selecionar os títulos mais importantes para a notoriedade de um laboratório e fazer com que se avance no conhecimento das práticas dos pesquisadores.

Outra abordagem da revista é desenvolvida por Jean-Pierre Courtal, Jeanine Pochon e Claude Vilain (1994), em uma análise das redes semânticas constituídas para os descritores dos artigos indexados nos bancos de dados. Ela permite perceber a evolução de um conceito e contribuir, assim, ao desenvolvimento da didática das ciências.

Estas diversas publicações mostram, portanto, o interesse que representa a revista científica para a pesquisa. Ela é uma fonte essencial de informação para a ciência em curso de formação, um indicador da atividade científica de grupos de pesquisadores e um indicador da evolução de uma ciência. Isto explica por que os profissionais da informação que trabalham nas unidades de formação e de pesquisa -laboratórios e bibliotecas universitárias - preocupam-se com a criação ou com os meios disponíveis para melhor alcançar a informação.

REVISTAS, PROFISSIONAIS DA INFORMAÇÃO E PESQUISADORES
Nestes processos de pesquisa e difusão de conhecimentos, os profissionais das bibliotecas têm um papel fundamental a exercer tanto no ato de compatibilizar os serviços bibliográficos, como na modernização da pesquisa pela utilização das tecnologias (Souza H., 1990). Regina Cianconi (1990) insiste particularmente na necessidade de formação inicial e de formação continuada das equipes de documentação para a pesquisa de artigos online.

A possibilidade de se utilizarem as tecnologias da informação nas bibliotecas em geral e principalmente nas bibliotecas universitárias é vantajosa para a pesquisa. A necessidade de se dispor de um equipamento próprio e de se utilizarem redes de bancos de dados locais ou estrangeiras é mencionada por Murilo Cunha (1994). Este autor, após breve histórico da introdução da Internet no Brasil, a partir de 1983, lista alguns serviços como o correio eletrônico e os protocolos de troca de arquivos como particularmente úteis aos pesquisadores.

Na França, os profissionais mostram a importância dos periódicos aos usuários à medida que eles se interessam pelas diversas ferramentas colocadas à sua disposição pelos bibliotecários. Pierre Belbenoit-Avich (1992b) mostra as possibilidades oferecidas pela British Library Document Supply Centre e o interesse pelos cd-roms e bancos de dados on-line no campo da medicina (1992a). Dominique Benoit e Hervé Le Crosnier (1994) fazem um inventário dos repertórios disponíveis na França e nos Estados Unidos para acesso aos periódicos. Trata-se, também neste estudo, dos diretórios de periódicos de vulgarização de alto nível normalmente assimilados a revistas, como Archeologie ou La Recherche.

O interesse se encontra também em analisar as realizações estrangeiras. Dominique Baudin (1990) descreve o Catalogue Collectif national des periodiques allemands e sua utilização para o empréstimo entre bibliotecas alemãs. Marie-Josee Vin (1994) analisa o Journal Citation Reports do Science Citation Indexproduzido pelo Institute for Scientific Information. Para ela, 
esta é uma boa ferramenta de medida da visibilidade de uma revista no domínio da astronomia, mas, para Yves Desrichard e Claudine Kleb (1994), o fator de impacto das revistas tal como é determinado por este instituto não pode ser considerado isoladamente para se escolherem os títulos que uma biblioteca deve assinar, caso se considere que as publicações em língua francesa que ele seleciona são raras. Estes autores aconselham considerar também as solicitações dos usuários, as estatísticas de empréstimo e os pedidos de empréstimo entre bibliotecas.

O que muda com a chegada da Internet? O que se torna a revista na rede? Como os profissionais adaptam seus trabalhos a esta mudança?

\section{PAPEL DA REVISTA ELETRÔNICA}

Após ter definido sucintamente a revista impressa e seu papel para a comunidade científica, Yves F. Le Coadic (1995) mostra a transição para a revista eletrônica. Esta nasceu em 1978, no New Jersey Institute of Techonology. Mas esta experiência e também uma segunda conduzida na Grã-Bretanha (1980-1984), bem como uma terceira realizada na França (1984-1987), fracassaram*. Dez anos depois, as tecnologias avançadas permitem a proposição de um meio com maior conformidade às necessidades dos leitores e mais econômico.

\section{Revista Eletrônica e Pesquisa Científica}

A revista eletrônica permite, atualmente, uma difusão rápida e contínua dos artigos, acesso permanente, qualquer que seja o lugar onde a pessoa se encontre, e maiores possibilidades de pesquisa. A utilização de ligações hipertexto e um conjunto de documentos associados ao artigo, como comentários, por exemplo, enriquecem a pesquisa documentária. Y. Le Coadic conclui, entanto, que este novo meio da literatura científica tem um futuro promissor.

\footnotetext{
* Trata-se do Eletronic information system para os Estados Unidos, Computer human factors para a Grã-Bretanha e do Journal Revue para a França.
}

Para Dinah Poblacion (1992), o crescimento exponencial do volume da literatura cinzenta é um meio de acompanhar o avanço da ciência nas sociedades modernas. Ela considera que o acesso a este tipo de literatura só será viável por meios tecnológicos. Para tanto, são necessários projetos de cooperação entre a Europa e a América no domínio da normalização da documentação em geral e do artigo científico em particular. Ela insiste sobre a importância da rapidez de acesso à informação possível - para ela, somente via comunicação eletrônica.

Antonio Miranda (1996) pensa que a extensão da infra-estrutura telemática não garante uma oferta de serviços de informação em bases mais justas e equiparáveis. Ele discute a questão da informatização como ideologia, sua globalização e o surgimento das bibliotecas virtuais. De fato, a inovação tecnológica exige grandes adaptações sociais. Baseando-se em S. Harnad, ele se interroga sobre o papel das publicações eletrônicas no desenvolvimento da indústria da informação, sem renunciar aos critérios de qualidade na produção de documentos originais.

Esta preocupação de qualidade das informações transmitidas é freqüentemente encontrada nos artigos sobrea revista eletrônica. Suzana Mueller (1994), por exemplo, a partir de uma recensão de estudos sobre os colégios invisíveis e um resgate dos fluxos da informação científica por meio das tecnologias, mostra que estas tecnologias oferecem facilidades para a comunicação. Atualmente, independentemente da distância geográfica, as revistas tornam possível uma grande difusão da informação sobre as pesquisas em curso ou concluídas.

Entretanto, estas novidades modificam o comportamento dos cientistas em relação ao processo de comunicação. A presença e a imensidão da rede Internet afetam a produção de pesquisas e de artigos científicos? Quais as alternativas para a substituição dos periódicos nacionais? O que isto muda do ponto de vista dos custos? Para Mueller, o problema mais fácil de se resolver é o referente aos aspectos tecnológicos. Mas são as outras questões ligadas, principalmente, à adaptação psicológica dos usuários ao estabelecimento da prioridade dos autores e à confiabilidade das informações as mais difíceis de serem resolvidas. É esta a razão pela qual outros pesquisadores (Mueller, Campello, Dias, 1996) apresentam um panorama dos canais de difusão da pesquisa no domínio da biblioteconomia e da ciência da informação no Brasil como a existência da literatura científica sendo um dos fatores mais importantes para o desenvolvimento da ciência. Os artigos manifestam preocupação constante pela qualidade, confiabilidade e credibilidade. Para manter esta qualidade, é necessária a avaliação destes documentos por referees.

Difundir artigos via Internet é um ato fácil. É possível publicar artigos já avaliados em dois sites específicos e se antecipar à publicação impressa. Mas, se a principal vantagem é a velocidade da divulgação que permite, em parte, a resolução das dificuldades ligadas à distribuição, os problemas àqueles que não têm acesso à rede continua. Por outro lado, se o acesso aos textos é possível sem a aquisição da revista, por que pagar pela assinatura? A Internet permitirá a superação de todos os obstáculos encontrados no Brasil pelas revistas científicas?

A fraca tiragem dos periódicos, a política de distribuição e a curta duração de vida de alguns títulos têm efeitos sobre a renovação das suas assinaturas ou novas subscrições. Este fenômeno não é recente. Ida Stumpf (1996) relembra isto através da história dos periódicos científicos há três séculos e a "revolução" dos anos 90, com a chegada da Internet. A revista eletrônica, ou seja, para esta autora, a revista disponível unicamente na rede deve possuir as mesmas etapas de elaboração que as revistas impressas: recepção e registro dos artigos, pré-avaliação pelo comitê editorial, avaliação dos editores na formatação do periódico, impressão e distribuição. A autora ainda enfatiza a velocidade e os baixos custos, especialmente durante as etapas de impressão e distribuição, mas o tempo necessário à avaliação pelos referees não é comentado. A inconveniência relevada pelo autor é a da interatividade, possível graças aos meios eletrônicos, que podem mudar 
os conteúdos dos trabalhos.

Packer, Antonio e Beraquet (1998), no editorial intitulado Rumo à publicação eletrônica, enfatizam que agora é o momento de posicionar a comunicação científica brasileira no movimento internacional de publicação eletrônica. Alertam sobre a importância da conexão de textos eletrônicos nacionais entre si e com textos e bases de dados bibliográficas internacionais. Comentam que somente a literatura publicada nos periódicos incluídos nos relatórios de citação do Institute for Scientific Information (ISI) pode ser sistemática e completamente avaliada. A intenção é que essas possibilidades estendam-se ao conjunto relevante dos periódicos científicos nacionais eletrônicos. Para isso, são necessários mecanismos integrados de controle da qualidade.

O Scientific Eletronic Library on-line (SciELO), produto de uma parceria com a Fundação de Amparo à Pesquisa do Estado de São Paulo (Fapesp), Centro Latino-Americano e do Caribe de Informação em Ciências da Saúde (Bireme) e de editores de revistas científicas, objetiva "desenvolver uma solução para a ampla implantação da publicação eletrônica no Brasil, América Latina e Caribe, com o propósito de aprimorar o controle, a visibilidade e a avaliação da literatura científica." (Packer et al, 1998, p.109)

Targino (1995) enfatiza a falta de preocupação com a confiabilidade e consistência dos dados ligados a quase instantaneidade da informação e a sua vida efêmera na rede. Ela, todavia, também considera as publicações disponíveis na Internet, para os pesquisadores dos países em desenvolvimento, como um meio de acesso em tempo real às informações provenientes de países cientificamente mais avançados.

Figueiredo (1995) faz um estudo comparativo das previsões de Lancaster sobre a "sociedade sem papel" com aquelas de outros autores e faz previsões para os anos 90. Para Lancaster, o sistema eletrônico melhora a dispo- nibilidade e a velocidade de difusão da informação. Aliás, o número total de periódicos publicados está ainda em fase de crescimento, mas seu número de páginas por edição diminui, porque os editores procuram aumentar seus lucros, apesar do mercado estar em declínio. Para Line, a tendência é o fornecimento de artigos isolados, em vez da edição de fascículos. Esta tendência influencia os editores, pois diminui os custos de estocagem, mantém os artigos no mercado e evita os riscos de produção inútil.

A preocupação maior é referente aos direitos autorais. Citando Lancaster, Figueiredo insiste sobre uma das barreiras, a mais importante, segundo ela, a barreira psicológica, que deverá ser eliminada pela nova geração habituada aos jogos eletrônicos.

Para alargar o debate, citemos o texto de Ferreira (1994). Ele aborda as mudanças provocadas na sociedade pelo desenvolvimento das tecnologias. $O$ mercado da informação aumenta, consideravelmente, os resultados da pesquisa, e os trabalhos acadêmicos são difundidos e comentados entre pares, nos fóruns eletrônicos, antes de serem impressos. A comunicação é gradativamente mais rápida e presente em todas as atividades humanas, não somente em forma impressa, mas também em forma numérica.

Estes textos que mostram um interesse vivo pela revista eletrônica são completados por estudos de situações particulares. Lima (1993), por exemplo, analisa a produção científica, em diversas instituições brasileiras de educação e de pesquisa no campo da agricultura. O artigo de revista é o meio de comunicação preferido por esta produção. Aqui, predominam os trabalhos de autores múltiplos, a comunicação eletrônica facilitando o intercâmbio.

Silva et al (1996) apresentam um panorama das diversas publicações eletrônicas - publicações em cd-roms e em disquetes - e, em particular, em revistas eletrônicas científicas disponíveis na Internet. Neste panorama, a medicina domina com $25 \%$ das revis- tas brasileiras exclusivamente eletrônicas. Considerando um exemplo concreto, eles fazem um balanço dos avanços da Ciência da Informação que coloca, no lugar, os processos necessários à sua implantação na rede mundial.

Gamboa (1998) relata sobre a base de dados Clase (Citas Latinoamericanas en Ciencias Sociales y Humanidades) y Periódica (Indice de Revistas Latinoamericanas en Ciências), produzida na Universidade Autônoma do MéxicoUnam. Oferece uma global e atualizada bibliografia que compila sistematicamente os trabalhos realizados e publicados na América latina. A base de dados Clase y Periódica tem, como fonte de informação, publicações periódicas e seriadas de caráter científico e técnico, editadas em países da América Latina e Caribe.

Michéle Battisti (1999) apresenta um relato de quatro eventos em que aborda a administração da informação e do conhecimento dentro da empresa do futuro: dinâmica das atividades documentárias, as revistas eletrônicas, estado-da-arte e perspectiva; o acesso à informação; descrição, armazenamento e busca da informação na web.

Donald King e Casol Tenopir (1998) analisam os aspectos econômicos da publicação de revistas acadêmicas e científicas. Avaliam o custo de produção versus dados de uso versus revista eletrônica versus revista em papel. Abordam também a viabilidade da utilização do artigo via empréstimo interbibliotecário e de comutação bibliográfica, priorizando assinaturas de revistas de baixo custo com índices freqüentes de consulta e optando por cópias dos artigos de revistas de custo mais elevados, com índice baixo de consultas.

A Unam vem desenvolvendo um projeto sobre um sistema de informação regional sobre as publicações científicas da América Latina e o Caribe, denominado "Latindex". Parte deste projeto é o Diretório de Publicações Científicas e Seriadas da América Latina e do Caribe, o qual pretende re- 
presentar o inventário da oferta atual de revistas acadêmicas e técnicas latinoamericanas. Parte deste trabalho já está disponível no site da Internet, assim endereçado: http://www. biblioweb.dgsca.unam.mx/latindex.

Segundo Gonçalves da Silva e Fernandes (1997) apud Gamboa (1998, p. 90) , pode se ver que estas bases de dados analisam mais revistas brasileiras que qualquer outro serviço de informação fora do Brasil.

Estes muitos artigos mostram que os pesquisadores de ciência da informação se preocupam fortemente com a evolução da revista eletrônica, a qual vai modificar as práticas de pesquisa e, em conseqüência, modificará o papel do bibliotecário como intermediário entre a informação e o pesquisador, que é o bibliotecário.

\section{REVISTA ELETRÔNICA, BIBLIOTECÁRIO E PESQUISADOR}

Neste contexto, Figueiredo (1995) descreve a atividade do Instituto Brasileiro de Informação em Ciência e Tecnologia (IBICT). Após breve histórico, ela mostra que o IBICT é um núcleo de competências no processo de tratamento, de acesso e de difusão eletrônica da informação, porque a publicação eletrônica de revistas, de periódicos, ou mesmo de livros que não têm equivalência impressa, é um problema para os profissionais da informação. $\mathrm{O}$ espaço físico necessário para estocar os documentos diminuirá. A classificação e a indexação desaparecerão e serão controladas pelos editores.

Se o fornecimento de documentos é, ainda, a principal atividade das bibliotecas, para Phil Barden (1996), no ano 2000 esta atividade será abandonada. É necessário que as bibliotecas tirem proveito das tecnologias, pois a informação em suporte eletrônico é um progresso para a pesquisa em medicina e a ciência em geral. O problema do papel do bibliotecário é, de agora em diante, questionado. É necessária a reinvenção das atividades documentais e a constituição de grupos novos associando o autor, o editor e o bibliotecário.

Estes diversos argumentos são reto- mados por Ghislaine Chartron (1995).

Ela deduz que existe uma transformação das funções das bibliotecas e da documentação a se considerar nas formações específicas. A intensificação do ensino da informática e a competência em um domínio particular do conhecimento serão indispensáveis aos bibliotecários. Para esclarecer este fenômeno, Lupovici (1995), da sociedade Jouve sytemes d'information, descreve a cadeia da edição eletrônica. Ela é relatada por Monique Gingoldf (1996) como um conjunto de sistemas eletrônicos colocados à disposição dos usuários das bibliotecas universitárias para responder à demanda de informação. A autora insiste na participação dos governantes pelo avanço da tecnologia em vários países, como Estados Unidos, Grã-Bretanha, Alemanha e Holanda.

Outra alternativa para visualizar a problemática é enfocada por Krzyzanowski e Taruhn (1998), em que descrevem o projeto de formação de consórcios no qual existe uma cooperação e compartilhamento de várias unidades de informação, facilitando o acesso à informação e aumentando o grau de satisfação dos usuários.

A inquietação quanto à difusão e acesso à informação não é só uma preocupação dos brasileiros, franceses, assim como podemos verificar no relato de Anna Prat (1998), quando decreve a preocupação de a Comissión Nacional de investigación Científica y Tecnológica do Chile (Conicyt) difundir inclusive a literatura nacional, que, por falta de recursos, não é divulgada e, por conseqüência, deixa de ser citada, implicando, inclusive, a avaliação da produção que é um dos indicadores para obtenção de recursos.

A autora salienta a importância do projeto SciELO, em que corroboramos por considerá-lo um avanço para o nosso país em termos de difusão da produção científica.

Em março de 1998, com o empenho do Projeto SciELO, foi realizado em São Paulo um seminário sobre avaliação da produção científica.

Em sua abertura, a palestra proferida por José Perez (1998) salienta a importância do projeto SciELO como instrumento importante para divulgar internacionalmente a nossa pesquisa.

O coordenador geral do Projeto SciELO, Rogério Meneghini (1998) comenta sobre a base de dados do Institute for Scientific Information (ISI) cuja base oferece ampla cobertura das mais importantes e influentes revistas publicadas em todo o mundo (Testa, 1998), onde grande parte da produção científica brasileira de qualidade não está incluída no ISI. Daí, então, a idéia do Projeto SCIELO, uma maneira de tornar mais visível e acessível a produção nacional via meio eletrônico.

Na França, se a demanda pode ser feita pelo intermédio da rede eletrônica, o documento em si circula pelo correio. Além disso, uma dificuldade deve ser superada para a livre circulação das informações: a dos direitos autorais. Anne Dujol (1996) precisa, aliás, que se trata, principalmente, de direito de editor. Na Internet, o texto integral continua minoritário e as revistas são após elas, seja uma reprodução das revistas impressas com um controle, graduações de peer reviewed, student reviewed a non peer reviewed, seja uma inteiramente eletrônica. Pessanha (1998) corrobora com a autora quando enfatiza a importância do sistema da avaliação da produção científica. Se consideramos o fato de que a ciência é produzida, na França, em sua maioria, nas universidades, esta "matériaprima" é vendida a baixo preço aos editores que a revendem a um preço alto às bibliotecas universitárias por meio de assinatura. Para Dujol, temos aí uma lógica de subdesenvolvimento, e por isso que Barden convida os bibliotecários a se interessarem na reorganização da informação.

\section{CONCLUSÃO}

Constatamos que, para todos os autores que publicaram sobre o tema, "publicações em periódicos" em Ciência da Informação, o Bulletin des Bibliothèques de France ou no Documentaliste-Sciences de l'information durante o período 1990-1996, este meio de co- 
municação foi considerado como o vetor formal de comunicação mais importante tanto para a difusão de conhecimentos, quanto para as trocas entre pares da comunidade científica.

Este consenso sobre o grande valor da revista científica como meio para levar a pesquisa a público é combinado com a constatação de que os diversos títulos com que contam a ciência brasileira têm problemas para se manter por razões de custo de impressão, pequena tiragem e dificuldades de distribuição. Do mesmo modo, na França, os orçamentos das bibliotecas universitárias não permitem mais responder à demanda dos usuários. A utilização da Internet parece ser uma solução. As tecnologias permitem eliminar as barreiras geográficas, os colégios invisíveis se desenvolvem, o fluxo de informação se transforma todo dia, e o acesso a alguns documentos é gratuito. Os obstáculos psicológicos à generalização do uso são uma preocupação importante para alguns autores, mas a preocupação dominante permanece a da manutenção, na rede, da qualidade das revistas impressas. O controle pelos pares, prova do nível científico dos artigos, é preconizado.

Ao término desta revisão bibliográfica, há evidências de que as formações dos profissionais da informação devem evoluir no sentido de maior consideração da comunicação via redes eletrônicas e de práticas de usuários das tecnologias. Outras questões terão de ser resolvidas, como a do direito autoral e editorial, a do orçamento das bibliotecas para responder à demanda em maior quantidade dos usuários e à da evolução dos modos de trabalho do pessoal.

\section{REFERÊNCIAS BIBLIOGRÁFICAS DAS RE-} VISTAS BRASILEIRAS

1. BARRETO, Aldo de Albuquerque. Mudança estrutural no fluxo do conhecimento: a comunicação eletrônica. Ciência da Informação, Brasília, v.27, n. 2, p. 122-127, maio/ago. 1998.

2. CIANCONI, Regina de Barros. Sistemas de recuperação em linha: educação versus atuação profissional. Ciência da Informação, Brasília, v. 19, n. 2, p. 131-136, 1990.

3. CUNHA, Murilo Bastos. As tecnologias de informação e a integração das bibliotecas brasileiras. Ciência da Informação, Brasília, v. 23, n. 2, p. 182-189, 1994.

4. FERREIRA, José Rincon. O impacto da tecnologia da informação sobre o desenvolvimento nacional. Ciência da Informação, Brasília, v. 23, n. 1, p. 9-15, 1994.

5. FIGUEREDO, Nice. As novas tecnologias: previsões e realidade. Ciência da Informação, Brasília, v. 24, n.1, p. 110-118, 1995.

6. FORESTI, Noris Almeida Bethonico. Contribuição das revistas brasileiras de biblioteconomia e ciência da informação enquanto fonte de referência para a pesquisa. Ciência da Informação, Brasília, v.19, n. 1, p. 53-71, 1990.

7. GAMBOA, José A . Acesso a revista latinoamericanas en internet: una opción través de las bases de datos Clase y Periódica. Ciência da Informação, Brasília, n.1, p.90-95, jan./abr. 1998.

8. KING, Donald W., TENOPIR, Carol. A publicação de revistas eletrônicas: economia da produção, distribuição e uso. Ciência da Informação, Brasília, v.27, n. 2, p. 176182, maio/ago. 1998.

9. KRZYZANOWSKI, Rosaly Favero, FERREIRA, Maria Cecília Gonzaga. Avaliação de periódicos científicos e técnicos brasileiros. Ciência da Informação, Brasília, v.27, n. 2, p. 165-175, maio/ago. 1998.

10. KRZYZANOWSKI, Rosaly Favero, TARUHN, Rosane. Biblioteca eletrônica de revistas científicas internacionais: projeto de consórcio. Ciência da Informação, Brasília, v.27, n. 2, p. 193-197, maio/ ago. 1998.

11. LIMA, Maria Fátima Bezerra Ferreira. Produção cientifica: revisão parcial da literatura brasileira com ênfase na área agrícola. Ciência da Informação, Brasília, v.22, n. 3, p. 233-236, 1993.

12. MENEGHINI, Rogério. Avaliação da produção científica e o Projeto SciELO. Ciência da Informação, Brasília, v.27, n. 2, p. 219-220, maio/ago. 1998.

13. MIRANDA, Antônio Lisboa Carvalho de. Globalizacion y sistemas de informacion: nuevos paradigmas e nuevos disafios. Ciência da Informação, Brasília, v.25, n. 3, p. 308-313, 1996.

14. MUELLER, Suzana Pinheiro Machado.O impacto das tecnologias de informação na geração do artigo cientifico: tópicos para estudo. Ciência da Informação, Brasília, v.23, n. 3, p. 309-317, 1994.
15. MUELLER, Suzana Pinheiro Machado, CAMPELLO Bernadete Santos, DIAS Eduardo José Wense. Disseminação da pesquisa em ciência da informação e biblioteconomia no Brasil. Ciência da Informação, Brasília, v.25, n. 3, p. 337-351, 1996.

16. OLIVEIRA, Margarida Pinto, ARAGÃO, Esmeralda Maria de. Padrões de comunicação cientifica na Universidade federal da Bahia. Ciência da Informação, Brasília, v.21, n. 3, p. 201-215, 1992.

17. PACKER, Abel Laerte. SciELO: uma metodologia para publicação eletrônica. Ciência da Informação, Brasília, v.27, n. 2, p. 109-121, maio/ago. 1998.

18. PACKER, Abel Laerte, ANTONIO, Irati, BERAQUET, Vera Sílvia Marão. Rumo à publicação eletrônica. Ciência da Informação, Brasília, v.27, n. 2, p. 107-108, maio/ ago. 1998.

19. PESSANHA, Charles. Critérios editoriais de avaliação científica: notas para discussão. Ciência da Informação, Brasília, v.27, n. 2, p. 226-229, maio/ago. 1998.

20. PEREZ, José Fernando. Seminário sobre avaliação da produção científica: sessão de abertura. Ciência da Informação, Brasília, v.27, n. 2, p. 217-218, maio/ago. 1998.

21. POBLACIÓN, Dinah Aguiar. Literatura cinzenta ou não convencional: um desafio a ser enfrentado. Ciência da Informação, Brasília, v.23, n. 3, p. 243-246, 1992.

22. RAMOS, Marcos Gonçalves. Modelos de comunicação divulgação científicas: uma revisão de perspectivas. Ciência da Informação, Brasília, v.23, n. 3, p. 340-348, 1994.

23. RODRIGUES, Maria da Paz Lins, MUALEM, Joana Rita Vilas Boas. Canais de comunicação utilizados pelos pesquisadores da Universidade Federal do Maranhão. Ciência da Informação, Brasília, v.22, n. 3, p. 237-241, 1993.

24. SILVA, Luiz Antonio Gonçalves da et al. Buscando soluções para se publicar na Internet: a experiência do IBICT com a Ciência da Informação on-line. Ciência da Informação, Brasília, v.25, n. 3, p. 454460, 1996.

25. SOUZA, Helena de Miranda Rosa. O papel do especialista de informação na modernização e profissionalização do conhecimento. Ciência da Informação, Brasília, v.19, n.2, p. 145-155, 1990.

26. STUMPF, Ida Regina Chitto. Passado e futuro das revistas cientificas. Ciência da Informação, Brasília, v.25, n. 3, p. 383386, 1996.

27. TARGINO, Maria das Graças. Novas tecnologias de comunicação: mitos, ritos ou ditos ? Ciência da Informação, Brasília, v.24, n. 2, p. 194-203, 1995.

28. TESTA, James. A base de dados ISI e seu processo de seleção de revistas. Ciência da Informação, Brasília, v.27, n. 2, p. 233-235, maio/ago. 1998. 


\section{REFERÊNCIAS BIBLIOGRÁFICAS DAS RE-}

The Interest of the Brazilian and French Library and Information Science Journals for the Electronic Journal from 1990 to 1999

\author{
Abstract \\ The scientific journal has been the object \\ of many publications in Brazilian and \\ French Information Sciences' journals. An \\ analysis of the scientific production in this \\ subject reveals the importance of $e$ - \\ journals in Brazilian and French \\ researches.
}

\section{Keywords}

E-Journals publications; Information science; Library studies in Brazil; France. v.39, n. 1, p. 61-69, 1994. VISTAS FRANCESAS

1. BATTISTI, Michéle, Journées d'étude: management de l'information, revues electroniques, droit d'accés, metadonnées. Documentaliste-Science l'information, Paris, v.36, n.1, p.18-28, 1999.

2. BARDEN, Phil. La fourniture de documents en l'an 2000. Bulletin des bibliothèques de France, Villeurbanne, v. 41, n. 1, p. 42-46, 1996.

3. BAUDIN, Dominique. Le catalog collectif national des périodiques allemand. Bulletin des bibliothèques de France, Villeurbanne, v.35, n. 6, p. 380-387, 1990.

4. BELBENOIT-AVICH, Pierre-Marie. Les bases plein-texte biomédicales et la fourniture de documents. Bulletin des bibliothèques de France, Villeurbanne, v.37, n. 6, p. 14-17, 1992.

5. BELBENOIT-AVICH, Pierre-Marie. Le British Library document supply centre. Bulletin des bibliothèques de France, Villeurbanne, v.37, n. 3, p.52-57, 1992.

6. BENOIST, Dominique, LE CROSNIER, Hervé. Périodiques et lecteurs: répondre à l'attente du public. Bulletin des bibliothèques de France, Villeurbanne, v.39, n. 4, p. 67-75, 1994.

7. CHARTRON, Ghislaine. Nouvelles problématiques pour l'IST. Documentaliste-Sciences de l'Information, Paris, v. 32, n. 6 , p. 289-295, 1995.

8. COURTIAL, Jean-Pierre, POCHON, Jeanine, VILAIN, Claude. L'étude d'un concept nouveau à partir de réseaux de motsclés: application à la didactique des sciences. Documentaliste-Sciences de I'Information, Paris, v.31, n. 4-5, p. 199204, 1994.

9. COUZINET, Viviane, BOUZON, Arlette, NORMAND, Raoul. Les doctorants livrés à la recherche documentaire: la pratique de la revue scientifique. Bulletin des bibliothèques de France, Villeurbanne, v.41, n. 6, p. 54-59, 1996

141, 1995.

14. LUPOVICI, Catherine. Le périodique électronique. Bulletin des bibliothèques de France, Villeurbanne, v.40, n. 2, p. 3237, 1995.

15. PIERRET, Jean-Dominique, HILAIRE, Gérard, QUONIAM, Luc, DOU, Henri. Etude bibliométrique des différents aspects de la mort subite du nourrisson traités dans les revues scientifiques. Documentaliste-Sciences de l'Information, Paris, v.31, n. 4-5, p. 211-217, 1994.

16. REMY, Danielle, RING, Blanche, VERGNES, Gisèle. Positionnement d'un département du CNRS dans la littérature scientifique. Documentaliste-Sciences de l'Information, Paris, v.33, n. 2, p. 91-97, 1996.

17. VERGNES, Gisèle, PICARD, Francis, MOSSETTI, Michel. Analyse bibliométrique des collaborations internationales des laboratoires de l'IN2P3 en 1984. Documentaliste-Sciences de I'Information, Paris, v.27, n. 6, p. 280-282, 1990.

18. VIN, Marie-José. Le SCI Journal citation reports: une application à l'astronomie. Documentaliste-Sciences de I'Information, Paris, v.31, n. 4-5, p.211217, 1994.

10. DESRICHARD, Yves, KLEB, Claudine. Le "journal citation reports" du " science citation index": une étude pour servir la politique documentaire d'un pôle d'acquisition spécialisé. Bulletin des bibliothèques de France, Villeurbanne,

11. DUJOL, Anne. Revues scientifiques médicales et droit d'auteur. Bulletin des bibliothèques de France, Villeurbanne, v.41, n. 1, p.75-82, 1996.

12. GINGOLD, Monique. Les bibliothèques universitaires et la fourniture électronique de documents. Bulletin des bibliothèques de France, Villeurbanne, v.41, n. 1, p. 70-74, 1996.

13. LE COADIC, Yves François. Les télé-revues: de la revue papier à la revue électronique. Documentaliste-Sciences de I'Information, Paris, v.32, n. 3, p. 135-

\section{Estera Muszkat Menezes}

Professora do Departamento de Ciência da Informação; Universidade Federal de Santa Catarina; pesquisadora convidada junto ao Laboratório de Estudos e Pesquisas em Ciências Sociais (Lerass).

\section{Viviane Couzinet}

Conferencista; professora-pesquisadora; responsável pela equipe de pesquisa; informação, comunicação entre pesquisadores (ICC); laboratório de estudos e de pesquisas em ciências sociais (Lerass).

E-mail: vcouzi@lera.iut-tlse3.fr
E-mail: estera@ced.ufsc.br 